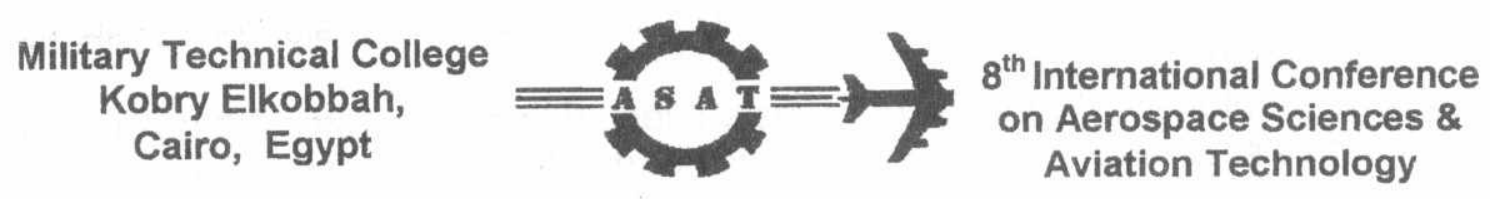

\title{
CHEMICAL PROCESSING OF ADVANCED LITHIUM ALUMINOSILICATE CERAMIC SYSTEM
}

\author{
W.I. Abdel-Fattah", M. Sh. Fayed", Sh. R. Gouda* and W. F. F. Mekky**
}

\begin{abstract}
:
During the past few decades, new developments in the use of ceramics in more advanced technological applications have drawn considerable attention. It is reported that certain ceramic compositions in the lithium aluminosilicate system have low thermal expansion coefficient and high degree of thermal shock resistance making them useful in specific applications. Being a novel technology for the chemical synthesis of ceramics, the sol-gel method was applied in this work. This process is based on the chemical hydrolysis and condensation reactions starting from molecular or colloidal precursors. Lithium aluminosilicate with molar composition $\mathrm{Li}_{2} \mathrm{O}: \mathrm{Al}_{2} \mathrm{O}_{3}$ : $3 \mathrm{SiO}_{2}$ was selected to be prepared via sol-gel technique. Tetraethoxysilane (TEOS), Lithium chloride $\left[\mathrm{LiCl} 2 . \mathrm{H}_{2} \mathrm{O}\right]$ and Aluminum nitrate $\left[\mathrm{Al}\left(\mathrm{NO}_{3}\right)_{3}, 9 \mathrm{H}_{2} \mathrm{O}\right]$ were used as precursors in this ceramic synthesis. The effect of $\mathrm{CH}_{3} \mathrm{COOH}, \mathrm{H}_{3} \mathrm{PO}_{4}$ and $\mathrm{HNO}_{3}$ acid catalysts on the synthesis method was studied. The prepared ceramic was analyzed by TGA, DSC, DTA, XRD, IR and SEM. The results were given, explained and discussed.
\end{abstract}

\section{KEY WORDS:}

LAS, Sol-Gel, Ceramics, Thermal Analysis and Structural Analysis.

\section{INTRODUCTION:}

One of the features which characterize materials is that most of the time they are not in themselves final products, nevertheless, every final product has to use materials. Advanced materials are characterized by high purity, high technical performance, increased integration of functions, increased variety and complexity and high value added.

In spite of its extensive use since the earliest civilizations, ceramics have drawn considerable attention in more advanced technological applications to satisfy the increased demands for improvements in specifications and reliability. The engineering properties of polycrystalline ceramics are controlled by the microstructure, which depends on the processing method. Advanced structural ceramics in addition to common properties, have relatively high mechanical strength

* Professor, Dpt. of ceramics, glass, refractories and building materials ,NRC

** Armed Forces of Egypt 
at high temperature, making them useful as components in heat engine, and electronic ceramics. Smart ceramics form intelligent materials and systems that comoine sensing and activating functions[1].

The Lithium aluminosilicate system was subjected to some studies. It is reported that the synthesis of the mentioned ceramic is due to the interest in preparing fast-ion conclucting glasses and glass-ceramics using sol-gel technology [2]. It is mentioned that one way to improve the ionic conductivity is to produce a silicate network with charınels and less dense to facilitate the alkali ion motion specially lithium ion. On the other hand, literatures show that certain ceramic compositions in the lithium aluminosilicate system have very low, zero or even negative expansion coefficient leadng them to be applied in specific fields [3]. The crystalline phases of the mentioned ceramic exhibit low thermal expansion coefficient and high degree of therrnal shock resistance [4].

The sol-gel process represents a novel method for the synthesis of non-metallic inorganic materials like glasses and ceramics. This process has the advantage of achieving nano-powder production with good homogeneity and high purity at lower tempierature. Starting from molecular or colloidal precursors in the sol form, a macromolecular network is obtained through hydrolysis and condensation reactions. The formed gel is then dried, calcined and sintered $[5,6]$.

\section{EXPERIMENTAL:}

Alcolnolic solutions of $\mathrm{LiCl} . \mathrm{H}_{2} \mathrm{O}$ (Koch-light) and $\mathrm{Al}\left(\mathrm{NO}_{3}\right)_{3} .9 \mathrm{H}_{2} \mathrm{O}$ (Fisher) were mixed and added to TEOS [Si( $\left.\left(\mathrm{OC}_{2} \mathrm{H}_{5}\right)_{4}\right]$ (Aldrich). The effect of catalyst (0.1:10 TEOS) was studied by introducing $\mathrm{H}^{+}$represented by $\mathrm{CH}_{3} \mathrm{COOH}, \mathrm{H}_{3} \mathrm{PO}_{4}$ and $\mathrm{HNO}_{3}$ a ratio of 0.1 . The precursors were refluxed for 1 hour at $85^{\circ} \mathrm{C}$. After cooling, the hydrolyzates were addeed to TEOS along with drying agent. Formamide being Lewis base like ammonium catalizer was added $\left(\mathrm{HCONH}_{2}, \mathrm{FA}\right.$ Prolabo) equal to alcohol and to control drying. The TEOS/water/ethanol molar ratio was 1/10/5. Stable gels were obtained at ambient conditions within 3-5 days, aged for one week, then, dried at $120^{\circ} \mathrm{C}$ till constant weight [7]

Thermal gravimetric analysis TGA (Netzch TG 209) and differential scanning calorimetry DSC (Netzch DSC 200) were adopted at $10^{\circ} \mathrm{C} / \mathrm{min}$ to follow the decomposition of the dried gels. Phase analysis of the gels calcined at $550^{\circ} \mathrm{C}$, $650^{\circ} \mathrm{C}, 750^{\circ} \mathrm{C}$ and $900^{\circ} \mathrm{C}$ was detected using $\mathrm{X}$-ray diffractometer (Philips, PW 1390) $2 \theta=2^{\circ} / \min \mathrm{Cu}$ Ko radiation. Semi quantitative Infrared spectral analysis with $\mathrm{KBr}$ disc technique (Philips PU 9712 spectrophotometer) and scanning electron microscope SEM (JEOL JSM.T20) were used .

\section{RESULTS AND DISCUSSION:}

The sol-gel method proved to be a good technique for the synthesis of advanced materials. It is used to prepare ceramics at relatively lower temperature than the traditional methods. In this paper lithium aluminosilicate ceramic was prepared starting with tetraethoxysilane (TEOS), lithium chloride $\mathrm{LiCl} . \mathrm{H}_{2} \mathrm{O}$ and aluminum nitrate $\mathrm{Al}\left(\mathrm{NO}_{3}\right)_{3} .9 \mathrm{H}_{2} \mathrm{O}$ via the sol-gel technique. The ceramic (LAS) was prepared by the precursor's hydrolysis followed by the condensation to form the gel under acid catalysis. The gel was then dried and calcined. Crack formation during drying is one of the most serious problems in the fabrication of ceramics specially thin films via sol- 
gel processing. Capillary forces and local differential stresses cause crack formation. So, in this work formamide was added as a drying-control chemical additive DCCA to the mixed precursors solution. It also aids in lowering the processing temperature. Percent yield of different catalyzed samples in table 1 showed that the highest yield is for the sample prepared with $\mathrm{HNO}_{3}$ while the lowest one is for the $\mathrm{CH}_{3} \mathrm{COOH}$. This may be due to the difference in dissociation constant and the weak acidity of acetic acid.

Table 1 : \% yield for prepared samples

\begin{tabular}{|c|c|}
\hline Acid & $\%$ Yield \\
\hline $\mathrm{CH}_{3} \mathrm{COOH}$ & 80.90 \\
\hline $\mathrm{H}_{3} \mathrm{PO}_{4}$ & 88.29 \\
\hline $\mathrm{HNO}_{3}$ & 92.77 \\
\hline
\end{tabular}

\section{1- Thermal Analysis:}

\section{a- Differential Scanning Analysis (DSC)}

Fig. 1 shows the DSC thermal curves of the prepared samples in which an exothermic peak at $273 \pm 1^{\circ} \mathrm{C}$ is characteristic for all samples. The formed peak may be due to the burn of organic residues chemically bonded to the gel structure. Another peak at $269^{\circ} \mathrm{C}$ for the $\mathrm{CH}_{3} \mathrm{COOH}$ catalyzed sample appear to interfere with the major one and this may be due to the chelating power of the acetate group which is confirmed with the high $\Delta \mathrm{H}$ value. Table 2 summarizes the DSC results where minimum $\mathrm{T}_{\mathrm{g}}$ of $313^{\circ} \mathrm{C}$ for the $\mathrm{HNO}_{3}$ sample suggest a lower degree of crosslinking than that of $\mathrm{CH}_{3} \mathrm{COOH}$ and $\mathrm{H}_{3} \mathrm{PO}_{4}$ leading to a more linear molecules while the other acids suggest a slightly branched ones.

Table 2 : Data obtained from DSC

\begin{tabular}{|c|c|c|c|c|}
\hline Acld & $T_{g}\left({ }^{\circ} \mathrm{C}\right)$ & 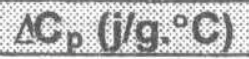 & Exo-Peak (\%O) & $\Delta \mathrm{H}(\mathrm{J} / \mathrm{g})$ \\
\hline $\mathrm{CH}_{3} \mathrm{COOH}$ & 329 & 2.72 & 269,272 & 710.1 \\
\hline $\mathrm{H}_{3} \mathrm{PO}_{4}$ & 329 & 2.99 & 273 & 596.1 \\
\hline $\mathrm{HNO}_{3}$ & 313 & 1.88 & 274 & 661.8 \\
\hline
\end{tabular}

\section{b- Thermo gravimetric Analysis (TGA):}

Fig. 2 for the TGA thermal curves confirms the results of DSC where the high exothermic peak reported corresponds to the loss in weight in all samples. The percentage weight loss shows that the $\mathrm{HNO}_{3}$ catalyzed sample has the lowest weight loss indicating high degree of polymerization (hydrolysis and condensation).

\section{c- Differential Thermal Analysis (DTA):}

The DTA thermal curve of $\mathrm{HNO}_{3}$ catalyzed samples shown in fig. 3 gives an idea about the crystallization, where two exothermic peaks appears at higher temperature than that of DSC. First at $763.74^{\circ} \mathrm{C}$ which may be due to crystallization, while the other on is at $945.06^{\circ} \mathrm{C}$ and supposed to be the sintering temperature. Peaks 
recorded in the DSC analysis does not appear in the fig as they have very low energy compared with those required for crystallization or sintering

\section{2- Structural Analysis:}

\section{a- X-ray Diffraction:}

X.RD of $\mathrm{HNO}_{3}$ catalyzed sample calcined at $550^{\circ}, 650^{\circ} \mathrm{C}$ and $750^{\circ} \mathrm{C}$ represented in fig. 4 indicate the start of crystallinity at $750^{\circ} \mathrm{C}$, and that all for all prepared samples calcined at $900^{\circ} \mathrm{C}$ shown in fig. 5 confirms the DTA results where complete crystalline powders are obtained.

\section{b- Infrared Analysis (IR):}

Fig. 6 shows the IR for samples calcined at $900^{\circ} \mathrm{C}$ which confirm results from DTA and XRD for the start of crystallinity.

The reported IR studies of LAS ceramics for the $\beta$-eucryptite [8] shows a series of very broad bands with a shoulder at $1085 \mathrm{~cm}^{-1}$. At $1050 \mathrm{Cm}^{-1}$ a medium peak with a shoulder together with an inflection at $1040 \mathrm{~cm}^{-1}$ are observed which are characteristic of $\mathrm{Si}(\mathrm{AL})-\mathrm{O}$ stretching vibrations.

Four very strong peaks appear at $1015,980,960$ and $940 \mathrm{~cm}^{-1}$. The IR spectra for the samples in fig 6 shows a series of peaks can be summarized in table 3 .

Table 3 : The assigned band and their wavenumber for different samples calcined at $900^{\circ} \mathrm{C}$

\begin{tabular}{|c|c|c|c|}
\hline \multirow{2}{*}{ Assignment } & \multicolumn{3}{|c|}{ Wavenumber $\left(\mathrm{cm}^{-1}\right)$} \\
\cline { 2 - 4 } & $\mathrm{H}_{3} \mathrm{PO}_{4}$ & $\mathrm{CH}_{3} \mathrm{COOH}$ & $\mathrm{HNO}_{3}$ \\
\hline $\mathrm{O}-\mathrm{H}$ bridging & 3430 & 3430 & 3430 \\
\hline $\mathrm{Si}-\mathrm{O}-\mathrm{Al}^{6}$ & 1160 & 1160 & 1140 \\
\hline $\mathrm{Si}-\mathrm{O}-\mathrm{Al}{ }^{4}$ & 820 & 820 & 820 \\
\hline $\mathrm{Si}-\mathrm{O}$ strech & 1000 & 1020 & 1020 \\
\hline $\mathrm{Al}{ }^{6}-\mathrm{O}-\mathrm{Al}^{4}$ & 1000 & 1020 & 1020 \\
\hline
\end{tabular}

\section{3- Morphological Analysis:}

SEM for the samples calcined at $900^{\circ} \mathrm{C}$ appears in fig. 8 where sample prepared with $\mathrm{HNO}_{3}$ shows high crystallinity and the fused edges indicates partial sintering which confirms the second DTA peak.

\section{CONCLUSION:}

The sol-gel method proved to be a good technique for the ceramic synthesis at low temperature. Lithium aluminosilicate was prepared at a temperature of $750^{\circ} \mathrm{C}$ lower than that used in the traditional which exceed a temperature of $1000^{\circ} \mathrm{C}$ [3]. The o otained samples have lower crystallization and sintering temperatures. Among used acids $\mathrm{HNO}_{3}$ stands as the best one for preparing linear highly polymerized gel with a good microstructure and crystallinity. 


\section{REFERENCES:}

[1] Mekky, W.F.F., "Ceramics for advanced applications", M.Sc. thesis, M.T.C. 1998.

[2] Ho, S.F., Szu, S.P. and Klein, L.C., "Solid-state ${ }^{29}$ Si and ${ }^{7}$ Li nuclear magnetic resonance spectroscopic studies of lithium aluminosilicate gels", Chemical processing of advanced materials, L.L. Hench and J.K. West, John wiley \& Sons, 1992.

[3] Abdel-Fattah, W.I. and Abdellah, R., "Lithia porcelain as promising breeder candidates-I. Preparation and characterization of $\beta$-Eucryptite and $\beta$-Spodumene porcelain.", Ceramics International, No. 23, pp 463-469, (1997).

[4] Abdel-Fattah, W.I., Fadel, M.A. and Abdellah, R., "Lithia porcelain as promising breeder candidates-II. Structural changes induced by fast neutron irradiation", Ceramics International, No. 23, pp 471-481, (1997).

[5] Livage, J., Henry, M. and Jolivet, J.P., " Inorganic polymerization in aqueous solutions", Chemical processing of advanced materials, L.L. Hench and J.K. West, John wiley \& Sons, 1992.

[6] Brinker, C.J. and Scherer, G.W., "Sol-Gel Science", Academic Press, 1990.

[7] Abdel-Fattah, W.I., Fayed, M. Sh., Gouda, Sh. R. and Mekky, W. F. F. " $\beta$ Eucryptite LAS via sol-gel route", $9^{\text {th }}$ international workshop on glasses, ceramics hybrids and nano-composites from gels, to be published.

[8] Gadsden, J.A., "Infrared spectra of minerals and related inorganic compounds", Butterworth, 1975. 


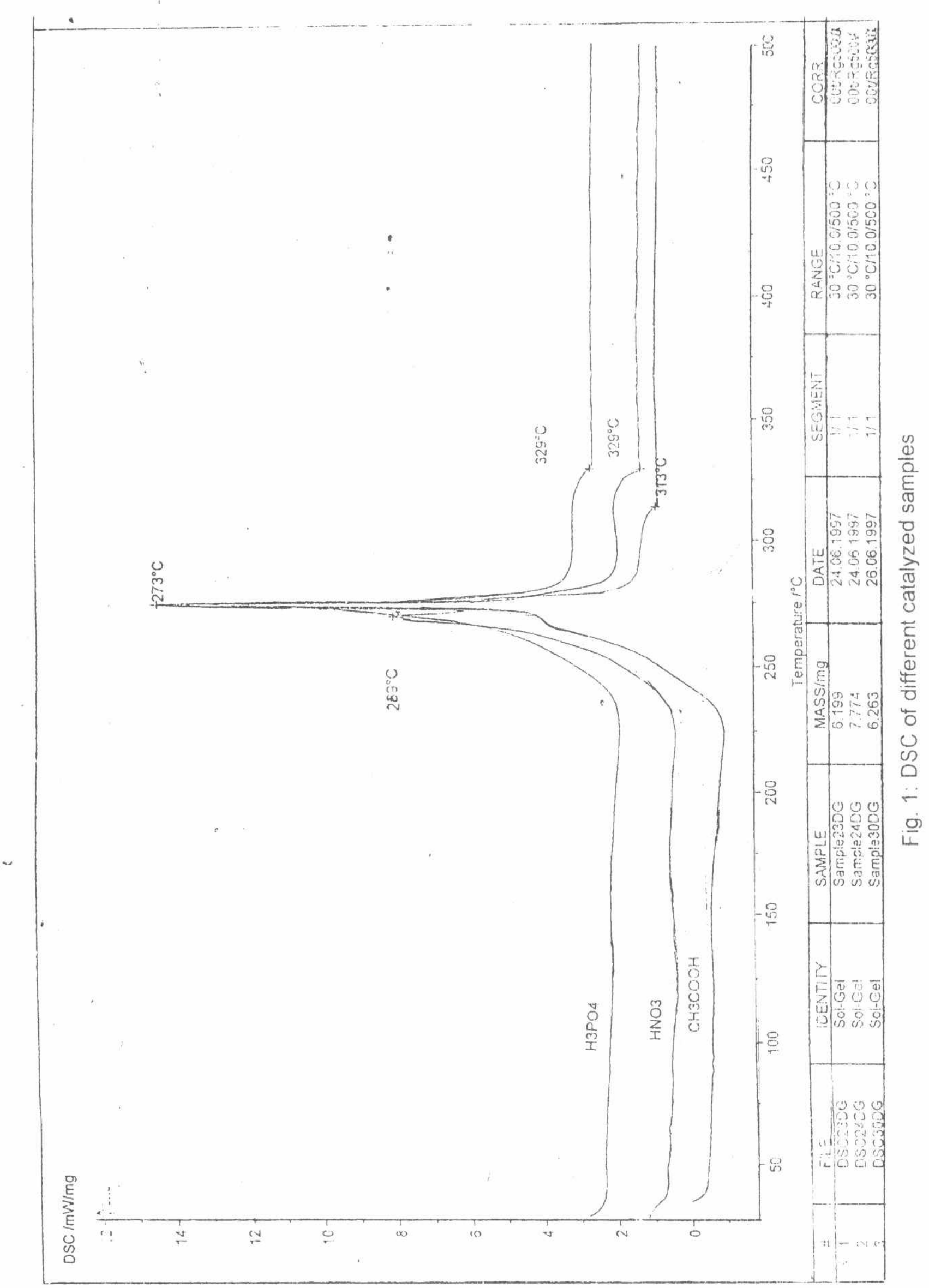




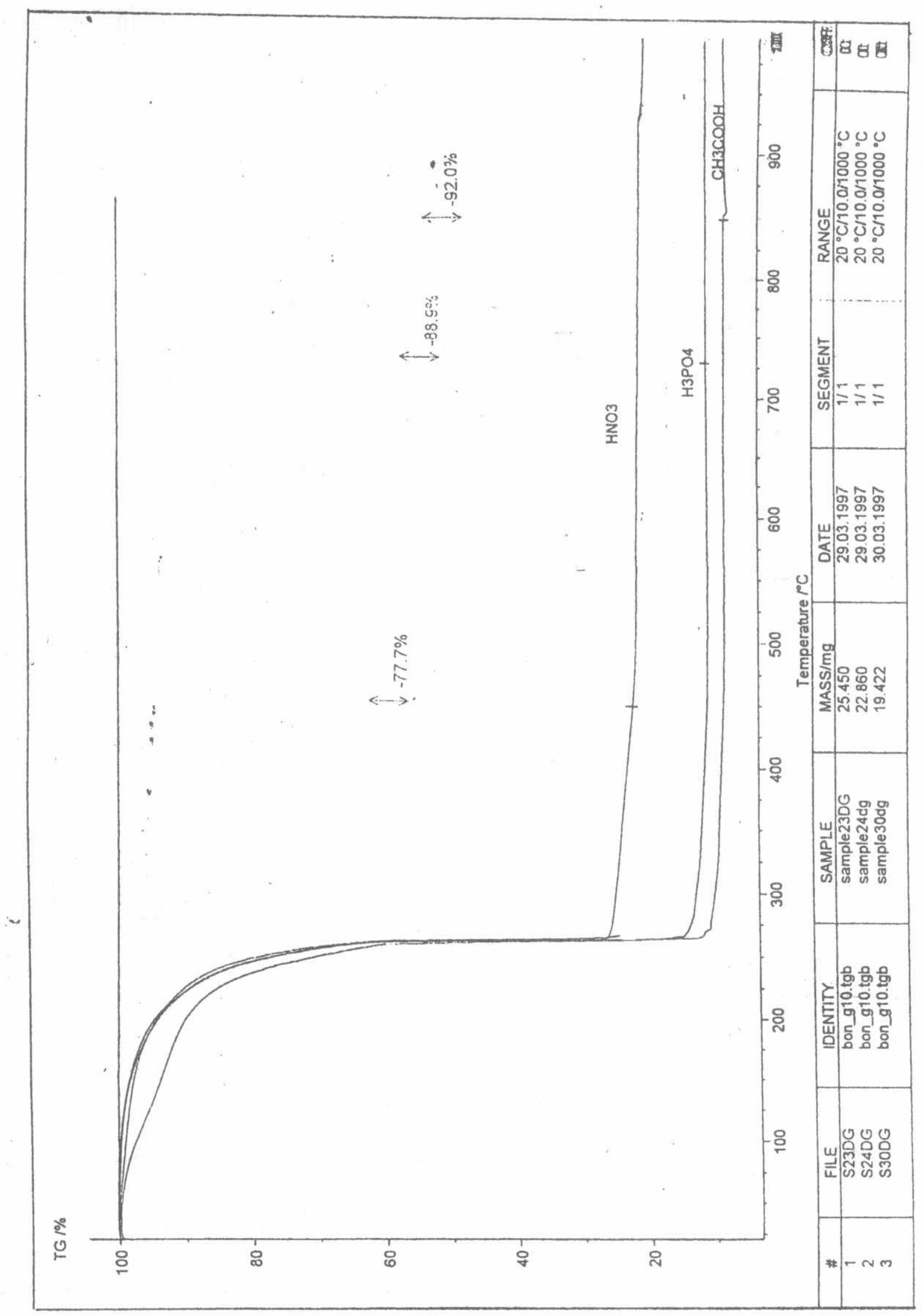

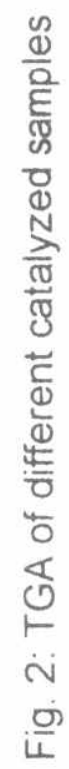




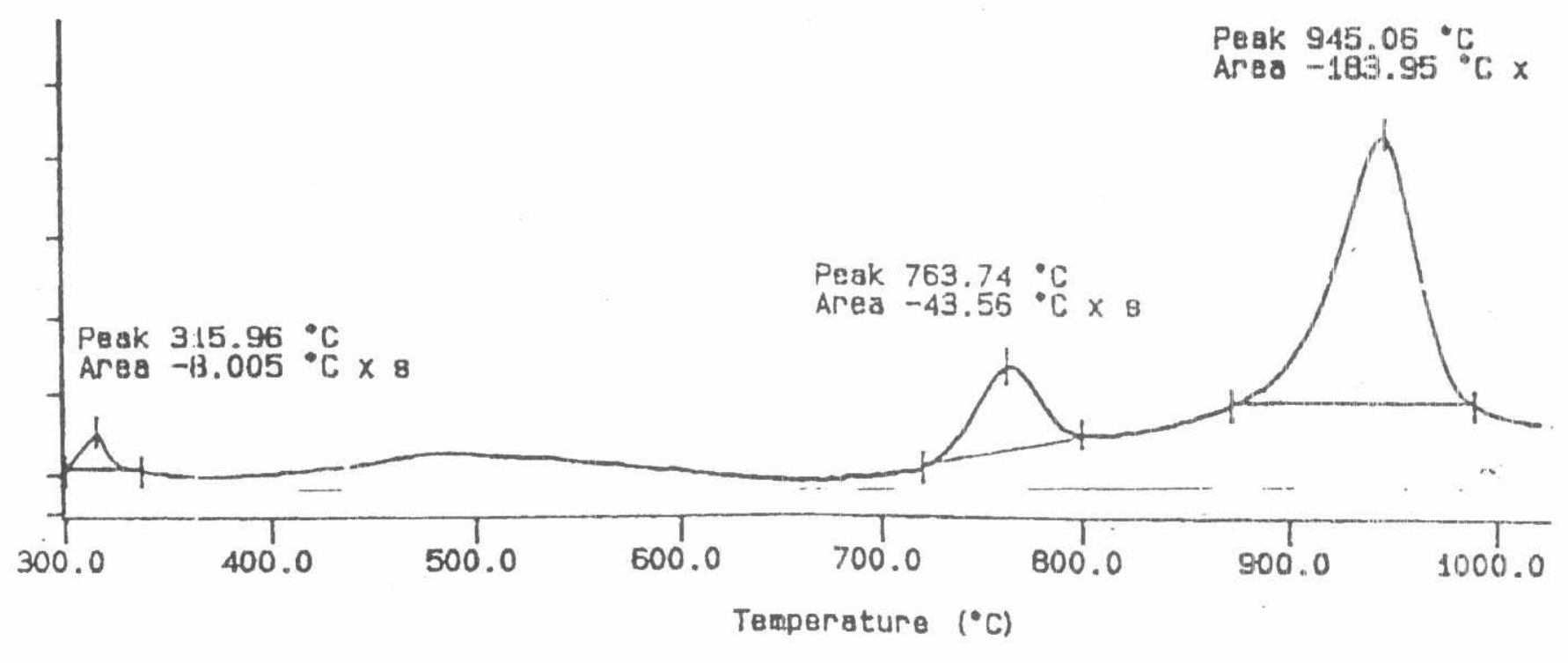

Fig. 3: DTA of sample prepared using $\mathrm{HNO}_{3}$ catalyst

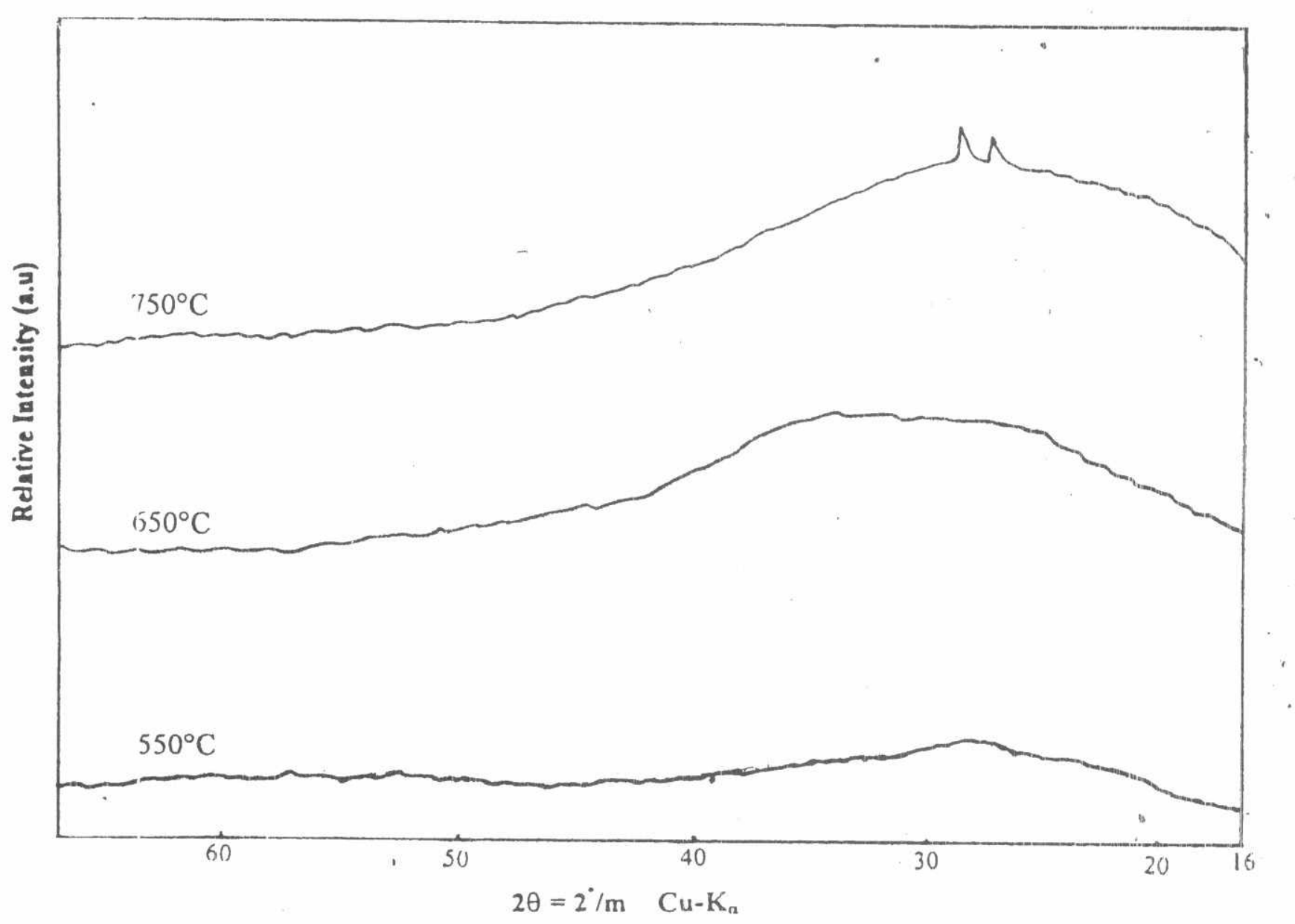

Fig. 4: XRD of sample prepared using $\mathrm{HNO}_{3}$ catalyst calcined at different temperatures 


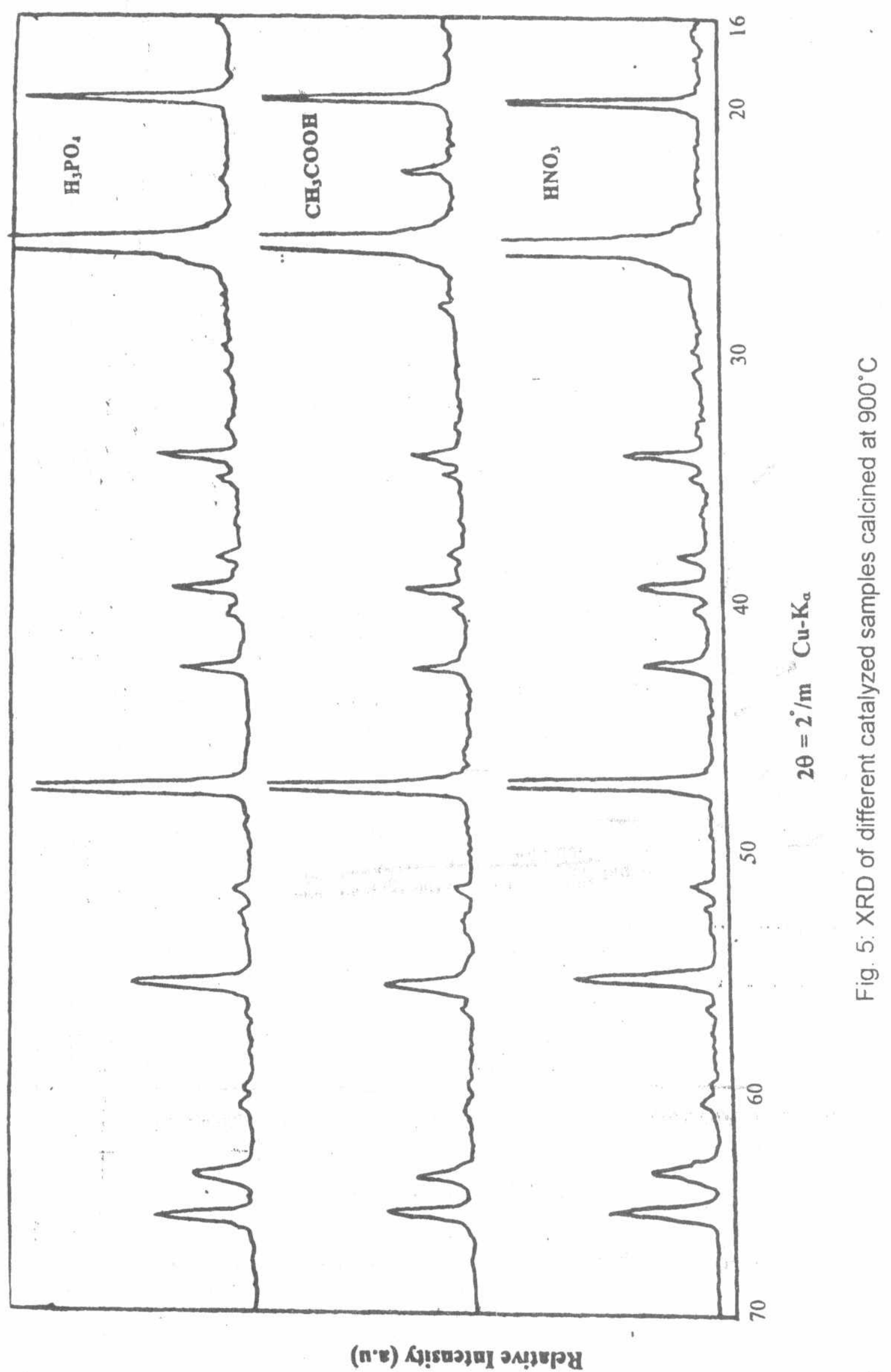




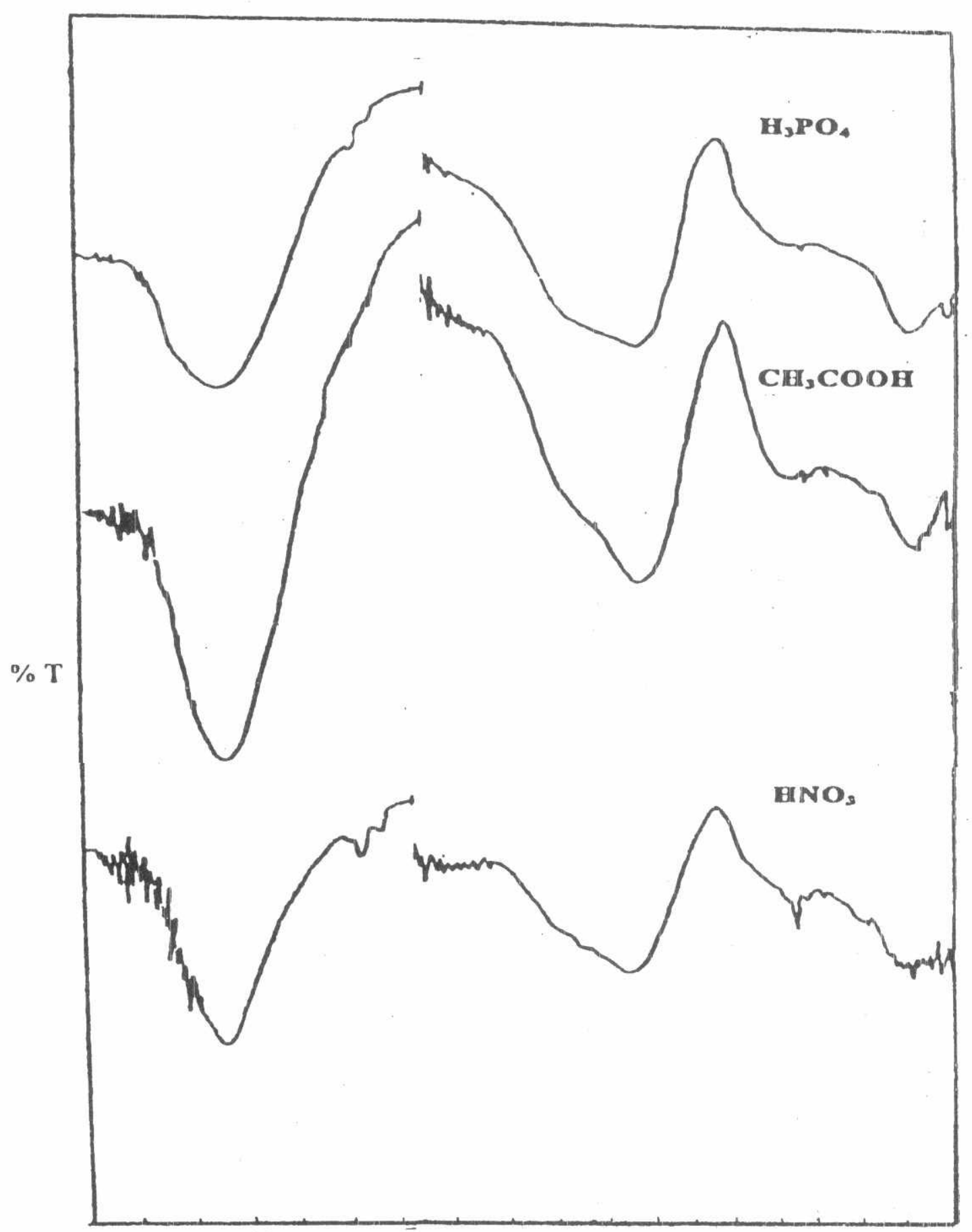

$4(100380036003400320030028001300120011001000900800700600500400300200$

Wavenumber $\left(\mathrm{Cm}^{-1}\right)$

Fig. 6: IR of different catalyzed samples calcined at $900^{\circ} \mathrm{C}$ 
a
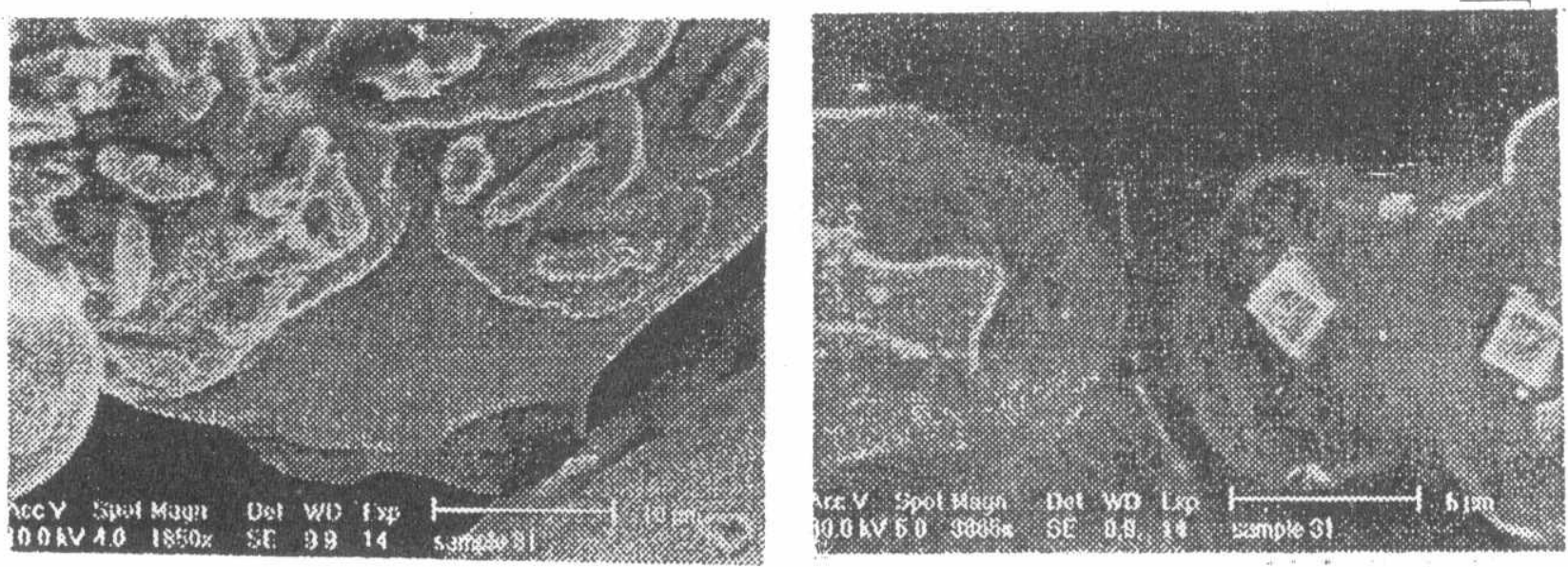

b
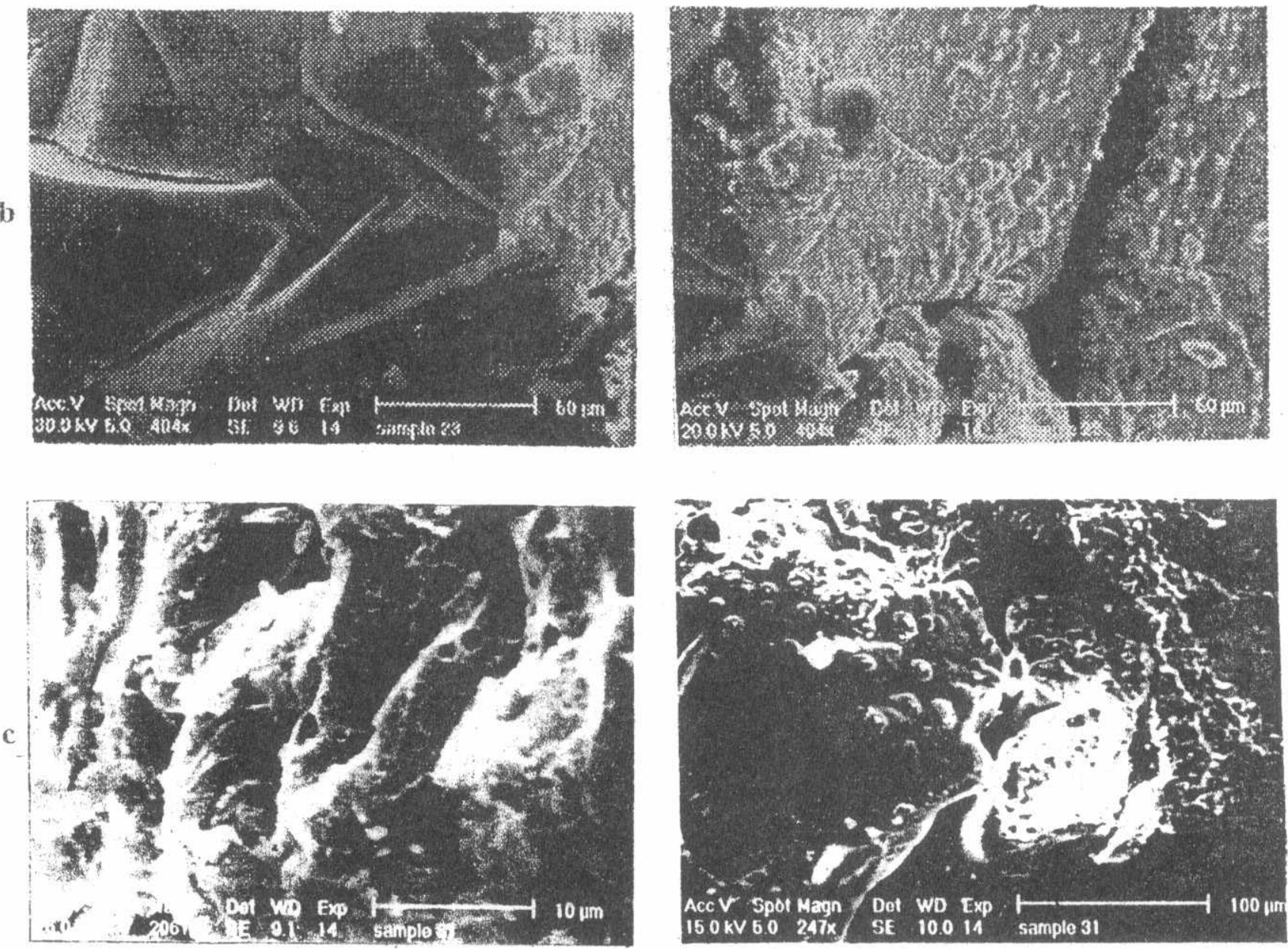

Fig. 7: SEM of different catalyzed samples calcined at $900^{\circ} \mathrm{C}$ 